\title{
Tobacco use and asking prices of used cars: prevalence, costs, and new opportunities for changing smoking behavior
} Georg E Matt*1, Romina Romero², Debbie S Ma ${ }^{1}$, Penelope JE Quintana ${ }^{3}$, Melbourne F Hovell ${ }^{3}$, Michael Donohue ${ }^{4}$, Karen Messer ${ }^{4}$, Simon Salem¹, Mauricio Aguilar ${ }^{1}$, Justin Boland ${ }^{1}$, Jennifer Cullimore ${ }^{1}$, Marissa Crane ${ }^{1}$, Jonathan Junker ${ }^{1}$, Peter Tassinario ${ }^{1}$, Vera Timmermannn ${ }^{1}$, Kristen Wong ${ }^{1}$ and Dale Chatfield ${ }^{1}$

Address: ${ }^{1}$ Department of Psychology, San Diego State University, San Diego, USA, 2Joint Doctoral Program in Health Behavior Research, San Diego State University and University of California, San Diego, USA, ${ }^{3}$ Graduate School of Public Health, San Diego State University, San Diego, USA and ${ }^{4}$ Moores Cancer Center, University of California, San Diego, USA

Email: Georg E Matt* - gmatt@sciences.sdsu.edu; Romina Romero - rromero@projects.sdsu.edu; Debbie S Ma - debbie.s.ma@gmail.com; Penelope JE Quintana - jquintan@mail.sdsu.edu; Melbourne F Hovell - mhovell@projects.sdsu.edu; Michael Donohue - mdonohue@ucsd.edu; Karen Messer - kmesser@ucsd.edu; Simon Salem - simonsalem@ hotmail.com; Mauricio Aguilar - maguilar@projects.sdsu.edu; Justin Boland - boland.justin@gmail.com; Jennifer Cullimore - jennijc55@yahoo.com; Marissa Crane - marissac@gmail.com; Jonathan Junker - jjunker21@hotmail.com; Peter Tassinario - pete.tassinario@gmail.com; Vera Timmermann - vera.timmermann@gmx.de; Kristen Wong - kristenjanelle19@yahoo.com; Dale Chatfield - dchatfield@sciences.sdsu.edu

* Corresponding author

\section{Published: 31 July 2008}

Tobacco Induced Diseases 2008, 4:2 doi:10.1186/1617-9625-4-2
Received: 19 June 2008

Accepted: 31 July 2008

This article is available from: http://www.tobaccoinduceddiseases.com/content/4/I/2

(c) 2008 Matt et al; licensee BioMed Central Ltd.

This is an Open Access article distributed under the terms of the Creative Commons Attribution License (http://creativecommons.org/licenses/by/2.0), which permits unrestricted use, distribution, and reproduction in any medium, provided the original work is properly cited.

\begin{abstract}
Secondhand smoke (SHS) causes premature death and disease in children and adults, and the scientific evidence indicates that there is no risk-free level of exposure to SHS. Smoking tobacco in a car can pollute the microenvironment of the car with residual SHS, leaving telltale signs to potential buyers (e.g., odor, used ash tray). This study examined (a) the proportion of used cars sold in the private party market that may be polluted with tobacco smoke and (b) whether asking prices of smoker and nonsmoker cars differed for cars of otherwise equivalent value. A random sample of I,642 private party sellers were interviewed by telephone, and content analyses of print advertisements were conducted. Findings indicate that $22 \%$ of used cars were advertised by smokers or had been smoked in during the previous year. Among nonsmokers, $94 \%$ did not allow smoking in their car during the past year. Only 33\% of smokers had the same restrictions. The smoking status of the seller and tobacco use in the car were significantly $(p<.0 I)$ associated with the asking price independent of a car's Kelley Blue Book value (KBB). Used nonsmoker cars were offered at a considerable premium above their $\mathrm{KBB}$ value (>11\%) and above comparable smoker cars (7-9\%). These findings suggest that community preferences are affecting the value of smokefree cars. New directions for research, tobacco control policies, and health education are discussed to further reduce smoking behavior, to help consumers make informed purchasing decisions, and to protect nonsmokers from SHS exposure.
\end{abstract}




\section{Background}

Secondhand smoke (SHS) contains more than 50 known human carcinogens and has recently been classified as toxic air contaminant $[1,2]$. SHS causes premature death and disease in children and adults, and the scientific evidence indicates that there is no risk-free level of exposure to SHS [1-3]. A growing number of local communities and states in the U.S. and in countries throughout the world are therefore adopting stricter policies to curb tobacco use in general and to reduce exposure to SHS exposure in particular [4-6].

The introduction of stricter tobacco control policies is often accompanied by health education campaigns about the harmful effects of tobacco use on smokers and vulnerable groups of nonsmokers [7-10]. The ultimate goals of these efforts are to improve public health through changing personal smoking behavior, community standards, and attitudes toward tobacco use and SHS $[2,8,11,12]$. According to the 2006 National Health Interview Survey [13], however, steady declines in smoking rates since the 1960 s appear to have stalled, remaining unchanged at $21 \%$ since 2004 . Thus tobacco control efforts remain a high public health priority, requiring renewed efforts to further reduce tobacco use and SHS exposure.

The present study examined the prevalence of tobacco use and asking prices of used cars in a community that has experienced extensive public health education campaigns since passing comprehensive statewide tobacco control legislation in 1988 [14]. We hypothesized that in such a community, smoke-free cars would be offered at a premium compared to smoker cars, controlling for other factors influencing the value of a car. If this is the case, future research may be warranted to better understand the effects of tobacco use on the value of personal property and how such consumer preferences could help further reduce tobacco use and SHS exposure.

\section{Tobacco Use in Cars}

Compared to research on smoking restrictions in the workplace, restaurants, and at home, relatively little is known about smoking restrictions in cars. Existing research suggests that smoking restrictions in cars are less common than those at home. In California, two out of three family cars had a complete smoking ban in 1996 and $1998[15,16]$, compared to almost four out of five homes with complete smoking bans. Among smokers, however, only $29 \%$ had a complete car smoking ban, and $43 \%$ had a complete home smoking ban. Similar patterns were observed in urban and rural settings of the U.S. outside of California. Halterman et al. [17] found that among urban households with smokers and children suffering from asthma only $64 \%$ had a complete ban on smoking in the home and $49 \%$ in the car. Kegler \& Halinka Malcoe
[18] examined low-income families of children in rural Oklahoma. They found that $49 \%$ of Native American households and $43 \%$ of Caucasian households banned smoking in the home, but only $35 \%$ and $40 \%$, respectively, banned smoking in the car. A deviation from this pattern was reported by King et al. [19] among AfricanAmericans who found a higher percentage of nonsmokers had car than home smoking bans (84\% vs. 74\%). Among smokers, however, only $17 \%$ and $21 \%$ had similar bans.

\section{Residual SHS Contamination of Used Cars}

When tobacco is smoked in the confined environment of a car, tobacco smoke pollutants can reach extremely high levels [20]. Volatile SHS components absorb into surfaces within minutes of emission, contaminating objects with which they come in contact. Subsequently, this residual SHS (also known as aged SHS or third-hand smoke $[21,22])$ is re-emitted into the air over days, weeks, and months, accumulates in dust, and deposits on surfaces [23-27], creating a route of exposure for drivers and passengers of smoker cars in the absence of concurrent active smoking.

Unlike mechanical or electronic defects, detecting the signs of previous tobacco use in a car often requires little technical expertise from a potential buyer. Routine tobacco use leaves many telltale signs to prospective buyers. Foremost is a distinct odor caused by the re-emission of SHS contaminants from surfaces and dust that were polluted during active smoking. Matt et al. [28] have shown that SHS odor and ash marks are significantly associated with the residual contamination of dust, surfaces, and the air in cars. It is this odor and other visible signs that can signal to a potential buyer that a car has been smoked in and that can be difficult and expensive to remove through cleaning or repairs.

\section{Private Party Sales of Used Cars in the U.S}

The used car market provides a particularly interesting opportunity to examine the value of a smoke-free personal environment, because a large and diverse cross-section of the general population in the U.S. sells and buys used cars. Moreover, a substantial portion of personal income is spent on the purchase and maintenance of cars. In 2005, 44.1 million used and 16.9 million new cars were sold in the U.S. [29,30]. These transactions totaled $\$ 780$ billion, $\$ 367$ billion of which were accounted for by used car sales. Approximately $30 \%$ of used cars were sold by private parties [30].

Although asking prices for used cars are often informed by published pricing guidelines (e.g., Kelley Blue Book), sellers can advertise their cars for any price, buyers can offer any price, and the eventual sales price is subject to the local market forces of supply and demand. Sellers typi- 
cally begin gauging an asking price by establishing the standard value of their used car based on its make, model, age, mileage, and condition. In addition, sellers often look up the asking prices of similar cars currently offered for sale by consulting the classified ads of local newspapers and used cars offered by dealers. Sellers then apply additional adjustments for factors believed to affect the value of a car in the community where it is sold that were not - or not sufficiently - included in the standard model. These adjustments may increase (e.g., chrome wheels; smoke-free car) or decrease the value of a used car (e.g., no air conditioning, smoker car). Further price adjustments follow if a car fails to sell and the seller is unable to remediate problems preventing a sale.

The Behavioral Ecological Model (BEM) provides a theoretical framework of the association between the values and norms of communities and the behaviors and preferences of individuals. Briefly put, BEM postulates that culture-wide social contingencies influence health practices at both the individual and the community levels. Changes in norms (e.g., tobacco use in the presence of nonsmokers) can initiate a cascade of social contingencies from the population to the individual levels that affect the strength of a given cultural characteristic (e.g., tobacco tolerance) [31,32]. Consequently, changes in individual health behavior (e.g., car smoking ban) can be initiated by changing social and economic contingencies at the population (e.g., smoker cars are worth less in the private party market) and individual levels (e.g., family members complain about stale tobacco odor in car). This study offered an opportunity to explore hypotheses about emerging social contingencies with respect to tobacco. We reasoned that cultural changes regarding tobacco use should lead to lower prices for cars offered by smokers than equivalent cars offered by nonsmokers. This would create new social and economic contingencies affecting tobacco use and SHS exposure among seller, buyers, and passengers.

\section{Methods \\ Participants}

The target population was private party sellers (age $\geq 18$ years) of used cars who advertised between January 2005 and April 2006 in the San Diego (USA) print editions of the Auto Trader magazine, a popular weekly publication of classified ads for used cars, and with phone numbers in the 619 and 858 area codes. Approximately 3,000 private party advertisements were published per week in the target area codes.

A random sample of 100 pages was drawn each week across all Auto Trader issues for different types of automobiles (i.e., domestic, Asian, European, sport utility models, newer and older models of trucks and vans) using a random number generator. The selected pages were sorted in the order in which the random numbers were generated. We called all eligible sellers on a page in the order of the sorted pages until we had recruited the target number of smokers each week $(1,2$, or 3$)$. Of the 2,590 sellers who were screened by phone for a study about the SHS contamination of cars, 2,081 (80\%) reported their smoking status, $1,667(64 \%)$ reported the smoking status of the car, and 1,642 (63\%) reported both. For analyses of asking prices $(\mathrm{N}=1,425)$, we excluded cars built before 1989 because car values could not be determined reliably. Table 1 provides information about asking price differences in the print advertisements, mileage, age, and make of cars by smoking status of the car and the seller. The Institutional Review Board at San Diego State University approved the research protocol.

Table I: Asking price, Kelley Blue Book value, mileage, age, and make of used cars, and percentage of used cars sold by a smoker and cars in which cigarettes have been smoked.

\begin{tabular}{|c|c|c|c|c|c|}
\hline & \multirow[t]{2}{*}{ All } & \multicolumn{2}{|c|}{ Smoke-Free Car } & \multicolumn{2}{|c|}{ Smoker Car } \\
\hline & & $\begin{array}{l}\text { Nonsmoker } \\
\text { Seller }\end{array}$ & $\begin{array}{l}\text { Smoker } \\
\text { Seller }\end{array}$ & $\begin{array}{l}\text { Nonsmoker } \\
\text { Seller }\end{array}$ & $\begin{array}{c}\text { Smoker } \\
\text { Seller }\end{array}$ \\
\hline Sample size & 1,642 & $\mathrm{I}, 274$ & 95 & 77 & 196 \\
\hline$\%$ of Used Cars & & 77.6 & 5.8 & 4.7 & 11.9 \\
\hline Asking Price ${ }^{\mathrm{a}}(\$)$ & 7,636 & 8,114 & 7,684 & 5,684 & 5,602 \\
\hline KBB Value $^{\mathrm{a}, \mathrm{b}}(\$)$ & 6,906 & 7,213 & 7,188 & 5,330 & 5,734 \\
\hline Mileage ${ }^{a}$ & 69,339 & 68,019 & 72,099 & 87,400 & 70,709 \\
\hline Age $^{a}$ (Years) & 6.0 & 5.9 & 6.0 & 6.0 & 6.7 \\
\hline \multicolumn{6}{|l|}{ Make } \\
\hline \% American & 50 & 51 & 40 & 48 & 48 \\
\hline \% Japanese & 33 & 32 & 39 & 43 & 34 \\
\hline \% European & 17 & 17 & 20 & 9 & 18 \\
\hline
\end{tabular}

a geometric means

b KBB: standard value of used car for private party sales based on Kelley Blue Book 


\section{Measures}

Telephone interview

Sellers were identified as smokers if they reported smoking cigarettes every day or on some days during the past year. Cars were identified as smoker cars if the seller reported that one or more cigarettes had been smoked in the car during the past year.

\section{Content analysis of print advertisements}

Data about the asking price, year, make, model, mileage, condition, and special features were obtained from the printed advertisement of the car or during the phone interview. For each car, the widely used KBB value was determined given the information provided in the printed advertisement, using the online valuation calculator [33]. If mileage information was omitted (15\% of cars), the $\mathrm{KBB}$ value was determined assuming 15,000 miles per year. While year, make, and mileage can be easily determined, condition, appearance, and special features often required judgment and interpretation. The condition of a car was coded as "good", unless the seller listed specific negative or positive characteristics, in which case the condition was downgraded to "fair" or "poor" or upgraded to "excellent". No KBB values are available for cars in "poor" condition (e.g., salvage title, major mechanical problems). When this was the case, a car was excluded from analyses $(<1 \%)$. To examine the reliability of the $\mathrm{KBB}$ value determination by coders of this study, intraclass correlations were calculated based on a random subsample of 50 cars coded by each of five coders. The ICC for individual ratings was 0.93 , indicating that $\mathrm{KBB}$ values were determined with good reliability.

\section{Statistical Analyses}

Statistical analyses were conducted using Stata version 9.2 [34]. Asking price and KBB values were log-transformed to normalize the model residuals. This was confirmed through graphical and quantitative analyses. Because cars sold by smokers and nonsmokers may differ in characteristics other than smoking status, it was important to adjust for these factors. Multiple regression analyses were conducted, in which the log-transformed asking price was the response variable and the log-transformed mean-centered $\mathrm{KBB}$ value and its quadratic and cubic terms were entered as covariates to statistically control for differences in the asking prices given the KBB valuation. We then investigated whether sellers may have applied different weights to the components of the standard valuation. Thus we added mileage, year, make, and condition of a car as additional covariates, and retained covariates in the model $\alpha<$ 0.05 . Finally, we entered dummy variables for smoking status of the seller, smoking status of the car, and interaction terms of all covariates and explanatory variables. No interaction effects were statistically significant ( $\alpha=0.05)$. We examined the robustness of model estimates through sensitivity analyses in which different transformations of asking prices and $\mathrm{KBB}$ values, robust variance estimates [35], bootstrapped regression coefficients, and alternative regression models (quantile and robust regression) were explored. Throughout these analyses, overall model fit, statistical significance for smoking status of sellers and cars, and effect sizes remained stable. The reported findings are based on log-transformed variables and models specifications outlined above.

We derived maximum likelihood estimates based on our sampling design to estimate the proportions of smokers and smoker cars in the target population. Briefly, we modeled the number of smokers who were not recruited and the number of smokers who were recruited using the negative binomial distribution. Variance estimates were derived via the delta method [36].

\section{Results}

\section{Smoking Status of Sellers and Cars}

Overall, 17.7\% (95\% Confidence Interval: $15.9 ; 19.6)$ of sellers reported themselves being smokers, $16.6 \%$ (14.8; $18.4)$ of used cars had reportedly been smoked in, and $22.4 \%(20.4 ; 24.4)$ of cars had either been smoked in or were being sold by a smoker. Among the nonsmokers, $5.7 \%(4.6 ; 7.1)$ had allowed smoking in their car during the previous year. Among smokers, 67.4\% (61.6; 72.6) had allowed smoking in their car. Table 1 provides additional detail on the smoking status of sellers and their cars.

\section{Smoking Behavior and Asking Price}

Linear regression models showed that the $\mathrm{KBB}$ value accounted for $84 \%$ of the variance in asking price $(p<$ $0.001)$, indicating that the asking prices closely matched the prices suggested by the KBB valuation model. In addition, there were statistically significant quadratic and cubic trends $(p<.001$; accounting for additional $1 \%$ variance). Further investigations of the nonlinear associations indicated that for cars with low KBB values $(<\$ 2,500)$ sellers raised the asking price comparatively more than for more expensive cars. Sellers made another adjustment based on the make of a car that went beyond the standard KBB valuation model, accounting for an additional $1 \%$ of the variance in asking price $(p<0.001)$.

Controlling for KBB value and make of car, smoking status of the seller and the car accounted for a significant proportion of variance $(F(2,1388)=6.37 ; p=0.002)$. Because the two variables were highly correlated $(r=0.62$; $p<.001)$, neither accounted for variance independent of the other when entered jointly in the model. When examined in separate models, smoking status of the car $(t(1391)=3.26 ; p=0.001)$ and of the seller $(t(1389)=$ 3.09; $p=0.002$ ) each accounted for significant propor- 
tions of variance in asking price (approximately $0.1 \%$ ) independent of KBB value and make of car. We address the practical significance of this effect below.

Figure 1 shows the association between $\mathrm{KBB}$ value and asking price for cars sold by smokers in which tobacco had been smoked and cars sold by nonsmokers in which no tobacco was smoked. Also shown is the reference line indicating cars offered at their standard KBB value (i.e., asking price $=\mathrm{KBB}$ value). The figure shows that the asking prices of smoker cars were consistently lower than those of nonsmoker cars of equivalent $\mathrm{KBB}$ value and were on average within $\pm 4-5 \%$ of their standard KBB value. In contrast, nonsmoker cars were consistently offered at a $10-13 \%$ premium above their KBB value.

Table 2 provides model estimates of asking prices based on smoking status of car and seller for cars at different KBB values, controlling for make, model, age, mileage, and condition of car. These estimates reveal that cars sold by smokers and cars that had been smoked in were offered at a significantly lower price than equivalent cars offered by nonsmokers and in which no smoking was reported. Because the regression models used log-transformed asking prices, the observed effects of smoking status of a car and a seller can be interpreted as differences in the percentage of asking price. That is, given a particular KBB value and model of car, the value of a car decreased by $7.7 \%$ if it had been smoked in compared to a car that was smoke-free. The value decreased by $7.5 \%$ if a car was sold by a smoker compared to an equivalent car sold by a non-

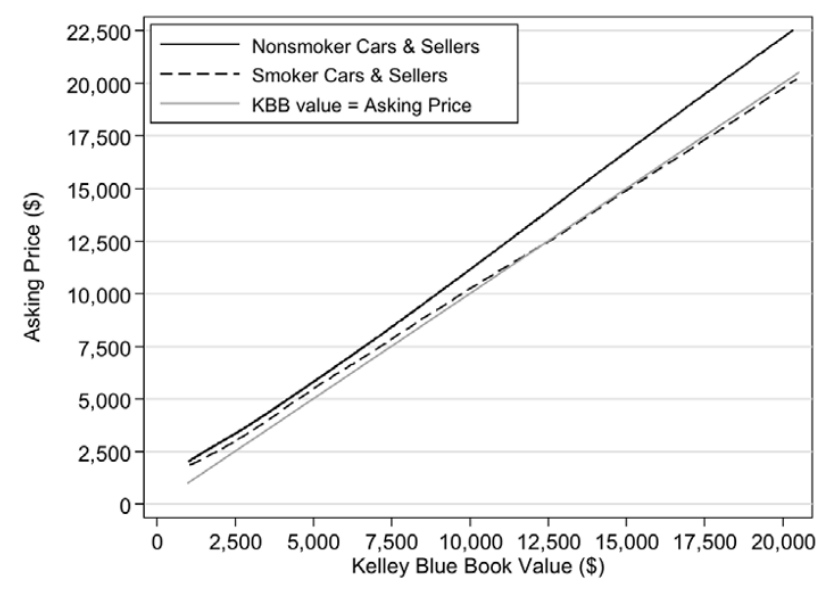

Figure I

Association between asking price and Kelley Blue Book value of used cars sold by smokers in which cigarettes have been smoked and by nonsmokers in which no cigarettes have been smoked (LOWESS fit lines). Also reported is a reference line for cars offered at the $K B B$ value. smoker. Finally, a car decreased in value by $9.0 \%$ if it was sold by a smoker who allowed smoking in the car compared to an equivalent car sold by a nonsmoker who prohibited smoking.

Table 2 also shows the percentage premium over KBB value that sellers asked for. For a car of median KBB value (i.e., \$7,363), nonsmokers who had not smoked in their car asked for a $13.5 \%$ premium over the KBB value. This compared to a $3.3 \%$ premium for an equivalent car sold by a smoker whose car had been smoked in.

\section{Discussion}

To the best of our knowledge this is the first study to examine the association between tobacco use in cars and their asking price in the private party used car market. Our findings show that one out of five used cars for sale in the San Diego (CA) metropolitan area were offered by smokers or had been smoked in during the previous year. While nine out of ten nonsmokers reported that no cigarettes had been smoked in their car during the past year, only one in three smokers reported to have had such a restriction. Finally, used nonsmoker cars were offered at a considerable premium above their $\mathrm{KBB}$ value and above comparable smoker cars. In the following we will briefly discuss limitations of this study and implications for tobacco control and consumer protection in the used car market.

\section{Limitations}

Findings from this study are based on a cross-sectional survey and self-reported information. Because of the social undesirability of smoking behavior and its likely negative impact on the sale of a car, we suspect that some misreporting took place such that the proportion of smoking sellers and smoker cars are likely to be higher than we determined.

While plausible, a preference for smoke-free personal environments is not the only possible explanation for the observed differences in asking price. The non-experimental nature of this study raises the possibility that the observed differences may be due to additional variables that affect both smoking behavior and the value of the car. To address this issue we included in our analyses as a covariate the standard $\mathrm{KBB}$ value of a vehicle. It is possible, however, that smoker cars overall are in worse condition than nonsmoker cars and are so in a way that was not measured by our rating of the condition and appearance of a car based on its print advertisement. It is also possible that potential buyers use the smoking-status of a seller or the tobacco odor of the car as a proxy of poor maintenance to negotiate a lower price and are not at all concerned about potential health effects or odor nuisance. Our study was also not able to examine whether smoking 
Table 2: Adjusted asking prices for cars of smokers and nonsmokers at different KBB values.

\begin{tabular}{|c|c|c|c|c|c|}
\hline \multicolumn{2}{|c|}{ KBB Value ${ }^{a}$} & \multicolumn{4}{|c|}{ Adjusted Asking Price in U.S. $\$$ b } \\
\hline Decile & U.S. \$ & $\begin{array}{l}\text { Nonsmoker } \\
\text { Car \& Seller }\end{array}$ & $\begin{array}{l}\text { Smoker } \\
\text { Seller }\end{array}$ & $\begin{array}{l}\text { Smoker } \\
\text { Car }\end{array}$ & $\begin{array}{l}\text { Smoker } \\
\text { Car \& Seller }\end{array}$ \\
\hline I & 2,080 & 2,893 & 2,677 & 2,670 & 2,634 \\
\hline 2 & 3,223 & 4,031 & 3,731 & 3,720 & 3,670 \\
\hline 3 & 4,354 & 5,187 & 4,803 & 4,787 & 4,722 \\
\hline 4 & 5,674 & 6,563 & 6,081 & 6,058 & 5,976 \\
\hline 5 & 7,363 & 8358 & 7,747 & 7,715 & 7,609 \\
\hline 6 & 9,186 & 10,324 & 9,574 & 9,531 & 9,399 \\
\hline 7 & 11,818 & 13,200 & 12,247 & 12,189 & 12,018 \\
\hline 8 & 14,900 & 16,600 & 15,409 & 15,333 & 15,113 \\
\hline 9 & 20,515 & 22,823 & 21,200 & 21,093 & 20,779 \\
\hline \multicolumn{2}{|c|}{$\begin{array}{l}\text { \% Difference: Asking Price vs. } \\
\text { Nonsmoker Car \& Seller }\end{array}$} & Referent & $-7.0 \%$ & $-7.7 \%$ & $-9.0 \%$ \\
\hline \multicolumn{2}{|c|}{$\begin{array}{c}\text { \% Difference: Asking Price vs. KBB } \\
\text { at median value }(\$ 7,363)\end{array}$} & $+13.5 \%$ & $+5.2 \%$ & $+4.8 \%$ & $+3.3 \%$ \\
\hline
\end{tabular}

aKelley Blue Book (KBB) values in U.S. currency for $\left.\right|^{\text {st }}$ to $9^{\text {th }}$ deciles.

bAsking prices were adjusted for linear, quadratic, and cubic effects of KBB values and make of car.

and nonsmoking buyers have similar preferences and how smoking status of the seller and tobacco odor of the car are considered in the purchasing decision.

This study focused on asking price and does not allow conclusions about actual sales prices. Although we expect that the sales price differences will exceed asking price differences, this should be demonstrated in future research. This study cannot provide explanations for the processes leading to the observed asking price differences. We also cannot rule out that smokers differed from nonsmokers in how they discounted asking prices for damages other than smoking or special features of their cars.

\section{Tobacco Use in Private Cars}

Our findings support existing research that smoking restrictions for private cars are less common than for homes. In 2005, 53\% of California's smokers reported living in a smoke-free home[37], but only $32 \%$ of the smokers in the present study reported that no cigarettes were smoked in the their car during the previous year. The relatively low prevalence of smoking bans in the cars of smokers raises the question whether cars may have become sanctuaries for smokers to light a cigarette while driving to and from places with smoking restrictions. While this smoking pattern protects nonsmokers when smokers drive alone, recent research [28] has demonstrated that it leads to the pollution of cars with residual SHS long after cigarettes have been smoked. Future research is needed to examine smoking behavior and restrictions in cars and how they may be influenced by restrictions in a smoker's home, workplace, and community.

\section{Tobacco Use and the Resale Value of Cars}

Our findings indicate that smoker cars have lower asking prices than comparable nonsmokers cars. From the perspective of the BEM, such asking price differences are to be expected in communities that value smoke-free personal environments, creating a greater demand for smoke-free cars such that sellers can ask for a premium over the car's KBB value and over comparable smoker cars. In contrast, asking price differences would not be expected in communities tolerant of or indifferent to SHS exposure and tobacco odor in cars and their effects on health and the value of a car. Consistent with the BEM, asking price differences contribute to a community-wide culture that encourages car smoking bans and discourages overall tobacco use. Thus, even if the motivation for discounting asking prices is not a perceived health risk, the financial consequences may contribute to establishing communitywide norms for not smoking in cars. This adds one more setting in which smoking may become socially unacceptable.

This study was conducted in a community in Southern California that has been highly sensitized to the health effects of tobacco use in general and SHS exposure in particular over 20 years of public health education efforts [38]. These efforts have contributed to reducing smoking prevalence in California from $26 \%$ to $14 \%$ between 1984 and 2005 [37], and, in 2002, 93\% of nonsmokers and $83 \%$ of smokers agreed that any exposure to SHS can be harmful to your health $[12,39]$. Our findings support the hypothesis that changes in collective values, smoking behavior, and attitudes toward SHS have influenced the market place, affecting the value of personal property and 
shaping purchasing decisions. Thus, monetary value of smoke-free environments in the market place may provide a useful outcome to evaluate long-term effects of tobacco control efforts at the level of communities. Because the health outcome of exposure to residual SHS in a car are not well understood, the observed differences in asking price may be a sign that the concerns of nonsmokers reach beyond recognized health risks and include concerns about the depreciation of personal property and quality of life. This is consistent with the increasing public debate about drifting smoke in multi-unit housing [40] and recent changes in local ordinances that led to smoking bans in city parks, on playgrounds, beaches, and sidewalks.

\section{Future Tobacco Control Efforts and the Used Car Market} From the perspective of tobacco control policies, the observed asking price differences are not only important outcomes of successful health promotion campaigns, but may suggest new strategies to further reduce tobacco use and SHS exposure. For instance, future tobacco control efforts could educate consumers about the effects of tobacco use on the value of used cars. Our findings suggest that many sellers are already cognizant of this effect. However, it is unclear whether this is equally known among smokers and nonsmokers and across different education, socio-economic, and ethnic groups. Health education campaigns could help motivate smokers to smoke less or quit altogether. Such campaigns could also empower consumers to assert their interests in smoke-free environments and in obtaining an appropriate discount if they choose to tolerate a smoker environment. Finally, consumer education campaigns would provide incentives to private sellers and dealers to advertise the smoking status of cars, allowing consumers to make informed purchasing decisions.

A more drastic approach would involve a change in the valuation model used by private parties, car dealers, banks, and insurance companies to value cars. Although it could be argued that such a step is unnecessary given the existing market response, it is worthwhile to consider this potential path as an explicit recognition of how a community values a car that may affect the health and driving experience of drivers and passengers.

Signs of tobacco use (e.g., odor, burn marks) are currently implicitly included among many factors that diminish the value of a car via their impact on appearance and overall condition. Our findings suggest that the smoking history of a car affects its value as much as many prominent features of a car that the KBB valuation models does consider. In November 2006, for instance, a 2000 Toyota Camry LE four-door sedan, 4-cylinder engine, automatic transmission, 77,000 miles, standard equipment, and in good condition was valued for private-party sale in the San Diego market at $\$ 7,695$. If this car had been offered by a smoker and had been smoked in, the asking price would have been about $\$ 700$ lower (i.e., $9 \%$ ). For this car to loose $\$ 700$ in $\mathrm{KBB}$ value, the car would have to miss all of the following standard features: air conditioning, power steering, power windows, power door locks, cruise control, and the dual front airbags. Admittedly, a car missing all of these features would probably sell in the market place for a much larger discount. Still, ignoring tobacco use in the valuation model of used cars disregards a feature of an automobile to which at least some communities appear to have assigned a considerable monetary value. From the perspective of the BEM, such a recognition would introduce an explicit incentive that may trigger further changes on the community and individual levels to reduce tobacco use and SHS exposure.

\section{Authors' contributions}

GEM conceived and designed the study, performed the statistical analyses, and drafted the manuscript. RR and DSM contributed to the design and coordinated the study, participated in the data collection and data analysis. PJEQ and MFH contributed the design of the study and drafted the manuscript. MD and KM contributed to the data analysis and drafted the manuscript. SS, MA, JB, JC, MC, JJ, PT, $\mathrm{VT}$, and KW contributed to the design the study and participated in the data collection. DC contributed to the design of the study. All authors read and approved the final manuscript.

\section{Acknowledgements}

This study was supported by grant \# 13-IT0042 from the California Tobacco Related Disease Research Program (TRDRP) and intramural support from the Center for Behavioral Epidemiology and Community Health at San Diego State University.

\section{References}

I. State of California Air Resource Board: Technical support document for the "Proposed identification of environmental tobacco smoke as a toxic air contaminant, Part A. [http:// www.arb.ca.gov/regact/ets2006/ets2006.htm]. Retrieved January I3, 2006

2. U.S. Surgeon General: The health consequences of involuntary exposure to tobacco smoke: A report of the Surgeon General Atlanta, GA: U.S. Department of Health and Human Services. Centers for Disease Control and Prevention, Coordinating Center for Health Promotion, National Center for Chronic Disease Prevention and Health Promotion, Office on Smoking and Health; 2006.

3. Repace J: Exposure to secondhand smoke. In Exposure analysis Edited by: Ott WR, Steinemann AC, Wallace LA. Boca Raton: Taylor \& Francis; 2007:201-235.

4. Americans for Nonsmokers' Rights: Smoke-free lists, maps, and data. [http://www.no-smoke.org/goingsmoke free.php?dp=d 3|p|40\#maps]. Retrieved June II, 2007. $(2007,4 / 2$ / 2007).

5. Fong GT, Cummings KM, Shopland DR: Building the evidence base for effective tobacco control policies: The international tobacco control policy evaluation project (the ITC project). Tob Control 2006, I 5(Suppl 3): I-2.

6. Semple S, Creely KS, Naji A, Miller BG, Ayres JG: Secondhand smoke levels in scottish pubs: The effect of smoke-free legislation. Tobacco Control 2007, I 6(2): I 27-I32. 
7. Gilpin EA, Emery SL, Farkas AL, Distefan JM, White MM, Pierce JP: The California tobacco control program: A decade of progress, 1989-1999 La Jolla: University of California, San Diego; 2001.

8. Fong GT, Cummings KM, Borland R, Hastings G, Hyland A, Giovino GA, Hammond D, Thompson ME: The conceptual framework of the International Tobacco Control (ITC) Policy Evaluation Project. Tobacco Control 2006, I5(Suppl 3):iii3-II.

9. Kadowaki T, Kanda H, Watanabe M, Okayama A, Miyamatsu N, Okamura T, Hayakawa T, Hishida K, Kita Y, Ueshima H: Are comprehensive environmental changes as effective as health education for smoking cessation? Tobacco Control 2006, I 5(I):26-29.

10. Harris F, MacKintosh AM, Anderson S, Hastings G, Borland R, Fong GT, Hammond D, Cummings KM, ITC Collaboration: Effects of the $\mathbf{2 0 0 3}$ advertising/promotion ban in the United Kingdom on awareness of tobacco marketing: Findings from the international tobacco control (ITC) four country survey. Tob Control 2006, I 5(Suppl 3):26-33.

I I. Pierce JP, Gilpin EA, Emery SL, Farkas AJ, Zhu SH, Choi WS: Tobacco control in California: Who's winning the war? An evaluation of the tobacco control program, 1989-1996 La Jolla, CA: University of California, San Diego; 1998.

12. Gilpin EA, White MM, White VM, Distefan JM, Trinidad DR, James L, et al:: Tobacco control successes in California: A focus on young people, results from the California tobacco surveys, 1990-2002 La Jolla, CA: University of California, San Diego; 2003.

13. Centers for Disease Control and Prevention: Cigarette smoking among adults - united states. Morbidity and Mortality Weekly Report 2006, 56(44): I I57-I I6I.

14. California Tobacco Control Section: Proposition 99 and the legislative mandate for the California tobacco control program. [http://www.dhs.ca.gov/tobacco/html/about.htm]. Retrieved June II, 2007

15. Norman G], Ribisl KM, Howard-Pitney B, Howard KA: Smoking bans in the home and car: Do those who really need them have them? Preventive Medicine 1999, 29(6 Pt I):58I-589.

16. Rohrbach LA, Howard-Pitney B, Unger JB, Dent CW, Howard KA, Cruz TB, et al:: Independent evaluation of the California tobacco control program: Relationships between program exposure and outcomes, 1996-1998. American Journal of Public Health 2002, 92(6):975-983.

17. Halterman JS, Fagnano M, Conn KM, Szilagyi PG: Do parents of urban children with persistent asthma ban smoking in their homes and cars? Ambulatory Pediatrics 2006, 6(2): II5-II9.

18. Kegler MC, Malcoe LH: Smoking restrictions in the home and car among rural Native American and white families with young children. Preventive Medicine 2002, 35(4):334-342.

19. King G, Mallett R, Kozlowski L, Bendel RB, Nahata S: Personal space smoking restrictions among african americans. American Journal of Preventive Medicine 2005, 28(I):33-40.

20. Ott W, Klepeis N, Switzer P: Air change rates of motor vehicles and in-vehicle pollutant concentrations from secondhand smoke. J Expo Sci Environ Epidemiol 2007.

21. Aitken RJ, Kenny LC, Soutar A: Measurement of personal exposure to PMIO in the non-workplace environment using passive sampling techniques Edinburgh, UK: Institute of Occupational Medicine; 200I.

22. Szabo L: Babies may absorb smoke residue in home. USA Today 2006. (August 6, 2006).

23. Daisey JM: Tracers for assessing exposure to environmental tobacco smoke: What are they tracing? Environmental Health Perspectives 1999, I07(Suppl 2):319-327.

24. Daisey JM, Mahanama KR, Hodgson AT: Toxic volatile organic compounds in simulated environmental tobacco smoke: Emission factors for exposure assessment. J Expo Anal Environ Epidemiol 1998, 8(3):313-334.

25. Destaillats H, Singer BC, Lee SK, Gundel LA: Effect of ozone on nicotine desorption from model surfaces: Evidence for heterogeneous chemistry. Environmental Science and Technology 2006, 40(6): $1799-1805$

26. Matt GE, Quintana PJ, Hovell MF, Bernert JT, Song S, Novianti N, Juarez T, Floro J, Gehrman C, Garcia M, Larson S: Households contaminated by environmental tobacco smoke: Sources of infant exposures. Tobacco Control 2004, I3(I):29-37.

27. Singer BC, Hodgson AT, Guevarra KS, Hawley EL, Nazaroff WW: Gas-phase organics in environmental tobacco smoke. I.
Effects of smoking rate, ventilation, and furnishing level on emission factors. Environ Sci Technol 2002, 36(5):846-853.

28. Matt GE, Quintana PJE, Hovell MF, Chatfield D, Ma DS, Romero R, et al.: Residual tobacco smoke pollution in used cars for sale: Air, dust, and surfaces. Nicotine \& Tobacco Research in press.

29. Bureau of Transportation Statistics: (2/2/2007). National transportation statistics: New and used passenger car sales and leases. [http://www.bts.gov/publications/ national transportation statistics/html/table 0 l $17 . \mathrm{html}]$. Retrieved June II, 2007

30. Mannheim: The 2005 used car market report Atlanta, GA: Mannheim, 6205 Peachtree Dunwoody Road, Atlanta GA 30328; 2005.

31. Hovell MF, Roussos S, Hill L, Johnson NW, Squier C, Gyenes M: Engineering clinician leadership and success in tobacco control: Recommendations for policy and practice in Hungary and central Europe. European Journal of Dental Education 2004, 8(Suppl 4):5 I-60.

32. Hovell MF, Wahlgren DR, Gehrman CA: The behavioral ecological model: Integrating public health and behavioral science. In Emerging theories in health promotion practice and research: Strategies for improving public health Edited by: DiClemente RJ, Crosby RA, Kegler M. San Francisco, CA: Jossey-Bass; 2002:347-385.

33. Kelley Blue Book: Values of used cars for private party sale. [http://www.kbb.com/kbb/UsedCars/default.aspx]. Retrieved June I I, 2007

34. StataCorp: Stata statistical software: Release 9.2 College Station, TX: Stata Corporation; 2006.

35. White $\mathrm{H}$ : A heteroscedasticity-consistent covariance matrix estimator and a direct test for heteroscedasticity. Econometrica 1980, 48:817-838.

36. Armitage P, Berry G, Matthews JNS: Statistical methods in medical research Malden, MA: Blackwell Science; 2002.

37. California Department of Health Services: California tobacco control update 2006. The social norm change approach Sacramento, CA: CDHS/TCS; 2006.

38. Traynor MP, Glantz SA: California's tobacco tax initiative: The development and passage of proposition 99. Journal of Health Politics, Policy and Law 1996, 2 I (3):543-585.

39. Independent Evaluation Consortium: Final report. Independent evaluation of the California tobacco control prevention and education program: Waves I, 2, and 3 (1996-2000) Rockville, Maryland: The Gallup Organization; 2002.

40. Semrad S: A new arena in the fight over smoking: The home News York Times; 2007. (November 5, 2007).

Publish with Bio Med Central and every scientist can read your work free of charge

"BioMed Central will be the most significant development for disseminating the results of biomedical research in our lifetime. "

Sir Paul Nurse, Cancer Research UK

Your research papers will be:

- available free of charge to the entire biomedical community

- peer reviewed and published immediately upon acceptance

- cited in PubMed and archived on PubMed Central

- yours - you keep the copyright 